\title{
Síntese e caracterização de MIP com fenilalanina visando sua aplicação na técnica de SPE
}

\section{Synthesis and characterization of MIP with Phenylalanine for their application in SPE}

\author{
Layla Talita de Oliveira Alves', Cynthia D'Avila Carvalho Erbetta', Christian Fernandes², \\ Maria Elisa Scarpelli Ribeiro e Silva ${ }^{1}$, Roberto Fernando Souza Freitas ${ }^{1}$ e Ricardo Geraldo Sousa ${ }^{1 *}$ \\ 'Laboratório de Ciência e Tecnologia de Polímeros - LCTP, Escola de Engenharia, \\ Universidade Federal de Minas Gerais - UFMG, Belo Horizonte, MG, Brasil \\ ${ }^{2}$ Laboratório de Controle de Qualidade de Medicamentos e Cosméticos, Faculdade de Farmácia, \\ Universidade Federal de Minas Gerais - UFMG, Belo Horizonte, MG, Brasil
}

*sousarg@ufmg.br

\begin{abstract}
Resumo
Polímeros Molecularmente Impressos (MIPs) são polímeros sintéticos que apresentam alta seletividade a uma molécula de interesse. O objetivo deste trabalho foi a síntese e caracterização de MIPs para aplicação na extração em fase sólida (SPE), visando a determinação de fenilalanina. Os MIPs foram sintetizados a partir do MAA, fenilalanina, EGDMA, AIBN, em clorofórmio. Também foi sintetizado o polímero não-impresso (NIP), para controle da seletividade dos MIPs. A dessorção da fenilalanina foi realizada em extrator Soxhlet. Os MIPs e NIP foram caracterizados pelas técnicas de análise: FTIR, UV-Vis, MEV, DSC e TG. O MIP apresentou maior capacidade adsortiva à fenilalanina do que o NIP, com uma taxa média de adsorção de 55\% comparada a $11 \%$ para o NIP. Por MEV o MIP apresentou superfície mais porosa, importante característica para aplicação em SPE. Os estudos realizados mostraram que o MIP sintetizado apresentou grande potencial para aplicação em técnica de SPE.
\end{abstract}

Palavras-chave: sintese e caracterização, MIP, fenilalanina, extração em fase sólida.

\begin{abstract}
Molecularly imprinted polymers (MIPs) are synthetic polymers that have high selectivity to a molecule of interest. The objective of this work was the synthesis and characterization of MIPs for use in solid phase extraction (SPE), in order to determine Phenylalanine. The MIPs were synthesized from the MAA, Phenylalanine, EGDMAAIBN, in chloroform. Non imprinted polymer (NIP) was synthesized to control the selectivity of MIPs. The desorption of Phenylalanine was carried out in Soxhlet extractor. The MIPs and NIP were characterized by the following analytical techniques: FTIR, UV-Vis, SEM, DSC and TG. MIP showed higher adsorption capacity to Phenylalanine than the NIP with an average rate of adsorption of 55\% compared to $11 \%$ for NIP. SEM MIP showed more porous surface, an important feature for use in SPE. The synthesized MIP in the present study showed great potential for use in SPE technique.
\end{abstract}

Keywords: synthesis and characterization, MIP, phenylalanine, solid phase extraction.

\section{Introdução}

O reconhecimento específico molecular é um requisito fundamental dos sistemas vivos. Assim, não é surpreendente que os cientistas ao longo dos anos tenham investido grandes somas de tempo e esforço na tentativa de mimetizar funções biológicas responsáveis pela seletividade inerente às interações enzima-substrato, antígeno-anticorpo e fármaco-receptor.

O conceito de impressão molecular para formação de anticorpos, processo no qual um antígeno era usado como molécula molde $(\mathrm{MM})$ para dar forma à cadeia polipeptídica de anticorpos, surgiu a partir da teoria de Pauling ${ }^{[1]}$. Em 1949, o trabalho de Dickey põe em prática a teoria de Pauling promovendo a utilização de absorventes específicos com memória inerente a uma dada molécula e capazes de se religar seletivamente à mesma ${ }^{[2]}$.

Dessa concepção, idealizou-se produzir um polímero rígido, com seletividade atribuída principalmente a sua estrutura tridimensional complementar à molécula molde, que pudesse atuar de forma similar ao anticorpo, ou seja, que pudesse efetuar seletivamente o reconhecimento molecular ${ }^{[3]}$.

Atualmente, essa técnica encontra-se bem estabelecida, sendo rotineiramente intitulada de Polímeros Molecularmente Impressos ou Molecularly Imprinted Polymers - MIPs, que são polímeros sintéticos que apresentam alta seletividade a uma molécula de interesse. Em geral, são facilmente 
sintetizáveis, podendo ser moldados de acordo com sua utilização, sendo sua síntese em geral pouco onerosa. Apresentam características vantajosas como estabilidade, robustez, seletividade, resistência a altas temperaturas e pressões e inércia química a ácidos, bases e solventes $\operatorname{orgânicos}^{[4]}$.

Em função dessas características, e dada sua alta seletividade, esses polímeros têm sido bastante empregados no preparo de amostras atuando como adsorventes em técnicas de separação, tais como, cromatografia líquida de alto desempenho ${ }^{[5]}$, eletroforese capilar ${ }^{[6]}$, eletrocromatografia capilar $^{[6]}$, cromatografia em camada delgada ${ }^{[7]}$, bem como em extração em fase sólida $(\mathrm{SPE})^{[8]} \mathrm{e}$ em microextração em fase sólida ${ }^{[9]}$, sendo ainda muito empregados nas áreas biológica, farmacológica e alimentícia ${ }^{[10]}$.

O emprego de MIPs como materiais adsorventes na técnica de SPE vem adquirindo destaque, sendo esse o principal campo de aplicação desses materiais, pois oferece alto grau de seletividade quando comparado com outros materiais, como cartuchos de sílica modificada $(\mathrm{C} 18)$ e resinas de troca iônica e, ao mesmo tempo, por serem mais estáveis que os adsorventes de origem biológica ${ }^{[11,12]}$.

A SPE é uma técnica amplamente empregada na extração e concentração de analitos, mesmo quando estão presentes em baixos níveis de concentração, na remoção de compostos interferentes em matrizes complexas e na mudança do meio de solubilização de um analito antes de sua análise cromatográfica. Sendo assim, a SPE é considerada uma técnica muito importante para o preparo de amostras ${ }^{[13]}$. Quando o material adsorvente é um MIP, a técnica recebe a designação de Molecular Imprinting Solid-Phase Extraction (MISPE) $)^{[14]}$.

Vários estudos foram realizados nos últimos anos comprovando a utilidade do método MISPE na extração de compostos em amostras biológicas, biofluidos, tecidos, água, solo e plantas. Os recentes desenvolvimentos em impressão molecular disponibilizaram polímeros que podem ser usados na detecção de fármacos, toxinas, agrotóxicos, aditivos alimentares, compostos tóxicos, entre outros ${ }^{[14]}$.

Um exemplo desses compostos tóxicos para o nosso organismo é a fenilalanina em excesso e seus catabólitos, que têm efeito tóxico nas funções somáticas e do sistema nervoso central, causando anormalidades como falhas no andar ou falar, hiperatividade, tremor, microencefalia, falhas no crescimento e retardo mental, sendo essa doença denominada fenilcetonúria ${ }^{[15]}$. A fenilcetonúria (PKU) é uma doença hereditária e está relacionada com a falta de uma enzima que é necessária para digerir a fenilalanina. Essa, como não é absorvida, passa a acumular-se no organismo até ser convertida em compostos tóxicos, designados por fenilcetonas (como o fenilacetato e a fenetilamina), que são expelidos pela urina. Os doentes com PKU que ingerem a fenilalanina sofrem de diferentes sintomas de toxicidade, incluindo atrasos mentais (especialmente em crianças) e distúrbios intelectuais nos adultos.

A fenilalanina (Phe) é um aminoácido essencial, ou seja, não é sintetizado pelo organismo humano, devendo ser obtido por meio da alimentação. É classificada como um aminoácido apolar e possui um anel aromático em sua cadeia lateral ${ }^{[15,16]}$. A fenilalanina se apresenta na forma de um cristal branco ou pó cristalino, sem odor ou com um leve odor característico e com um sabor levemente amargo. Prontamente solúvel em ácido fórmico, moderadamente solúvel em água e praticamente insolúvel em etanol. Dissolve-se em ácido clorídrico diluído. Apresenta valores de $\mathrm{pK}$ de 2,11 e 9,13, ponto isoelétrico (pI) em 5,48 e massa molar igual a $165,18 \mathrm{~g} \cdot \mathrm{mol}^{-1}$, além de ponto de fusão de $283^{\circ} \mathrm{C}^{[16]}$.

Os métodos usados para a remoção de fenilalanina baseiam-se na liberação desse aminoácido por hidrólise química ou enzimática, sendo posteriormente removido por tratamentos diferenciados. Vários métodos são utilizados para a remoção da fenilalanina, como adsorção em carvão ativado ou resinas de adsorção, cromatografia de troca iônica, peneira molecular ou filtração em gel, além de desaminação desse aminoácido pela enzima fenilalanina amônia liase. Apesar do uso do carvão ativado comercial ser uma das formas mais usadas para adsorção de aminoácidos, a utilização desse processo gera um aumento considerável no custo do processo, devido à necessidade de regeneração do adsorvente para posterior utilização. Além disso, existe a questão da não especificidade do carvão ativado comercial, que ao ser aplicado na remoção da fenilalanina em matrizes mais complexas, pode remover também outras substâncias, como, por exemplo, outros aminoácidos ${ }^{[15]}$. A escolha do método deve considerar a praticidade, a reprodutibilidade e a relação custo/eficiência de cada tratamento e ainda apresentar reconstituição e utilização viáveis. Tais limitações justificam a síntese de MIPs para a determinação de fenilalanina.

Diante do exposto, o objetivo deste trabalho foi sintetizar e caracterizar polímeros molecularmente impressos e não-impressos por meio da técnica de polimerização em massa, utilizando como molécula molde nos MIPs a fenilalanina, bem como estudar a aplicação desses polímeros na técnica de extração em fase sólida.

\section{Materiais e Métodos}

\subsection{Síntese dos MIPs e NIP}

O ácido metacrílico (MAA) foi utilizado como monômero funcional (MF), o etileno glicol dimetacrilato (EGDMA) como agente de reticulação (AR), o 2,2-azobisisobutironitrila (AIBN) como iniciador radicalar (IR), a fenilalanina (Phe) como molécula molde (MM) e o clorofórmio como solvente. A síntese dos MIPs foi realizada utilizando-se MF em excesso com relação à quantidade de Phe, pois, assim, procurou-se garantir que ele pudesse interagir com todos os sítios disponíveis no molde ${ }^{[17]}$. Optou-se por utilizar o EGDMA devido ao seu emprego em larga escala e com grande sucesso na síntese de $\mathrm{MIPS}^{[4,18]}$. O uso do iniciador AIBN foi devido ao fato dele sofrer homólise sob irradiação, por meio de uma lâmpada de vapor de mercúrio com emissão entre $345-365 \mathrm{~nm}$ para gerar os radicais livres ${ }^{[17]}$, condição essa utilizada nesse trabalho. O clorofórmio foi empregado como solvente pelo fato de ser apolar e com constante dielétrica baixa, favorecendo, dessa forma, a estabilidade das interações analito-monômero, além de fornecer um meio onde o analito e monômeros fossem solúveis.

Nesse estudo variou-se a razão "MM / MF", de forma a otimizar as condições de síntese, uma vez que esse fator influencia as propriedades de ligação e seletividade dos MIPs. 
Para o estudo da influência desse fator, foram sintetizados MIPs com diferentes razões "MM / MF", conforme mostra a Tabela 1. Nessa tabela também são apresentadas as quantidades de reagentes usadas na síntese do NIP-1. Como se pode ver, as quantidades são exatamente iguais às usadas para o MIP-1, exceto pela ausência de fenilalanina. Esse polímero foi usado como controle/comparação na adsorção dessa substância.

Todas as sínteses foram realizadas à temperatura de $4^{\circ} \mathrm{C}$ utilizando banho ultratermostático (Quimis, modelo Q214D2) e irradiação UV com lâmpada de mercúrio $(\lambda=365 \mathrm{~nm})$. A Phe, o MAA, o EGDMA e o clorofórmio foram adquiridos da Sigma-Aldrich. O AIBN foi adquirido da Polysciences. O solvente metanol grau HPLC foi adquirido da Merck e o ácido acético proveniente da Synth. Todos foram utilizados como adquiridos, ou seja, sem purificação prévia.

A MM foi pesada dentro de um frasco reacional (frasco ampola de $30 \mathrm{~mL}$ ) em balança analítica (Shimadzu, modelo AEL-405M). Em seguida, mediram-se os respectivos volumes de monômero ácido metacrílico e do solvente clorofórmio, por meio de micropipetas (Eppendorf), adicionando-os no frasco reacional contendo a MM e Phe. O frasco foi agitado manualmente onde, posteriormente, foi adicionado o agente reticulante EGDMA e o iniciador radicalar AIBN. Imediatamente após a adição dos reagentes ao frasco reacional, procedeu-se a purga com nitrogênio durante 5 minutos. $\mathrm{O}$ frasco foi então selado e colocado em banho ultratermostático (Quimis, modelo Q214D2) a $4^{\circ} \mathrm{C}$ adaptado com uma câmara contendo lâmpada UV $(365 \mathrm{~nm} / 100 \mathrm{~W})$. O tempo de polimerização foi de 6 horas $^{[5]}$.

Após a polimerização, o frasco foi retirado do banho e o clorofórmio (sobrenadante) foi retirado com o auxílio de uma pipeta. O polímero formado (sólido branco) foi secado em estufa a vácuo (Vacuoterm 6030A) por 12 horas a $65^{\circ} \mathrm{C}$ para remoção de solvente residual. Posteriormente ao processo de secagem, o frasco ampola de síntese foi quebrado e o polímero seco foi submetido à moagem utilizando um moinho analítico (IKA A11BS1). Os polímeros foram peneirados em tamizes, sendo utilizadas as partículas que ficaram na faixa granulométrica entre 0,042 e 0,050mm pelo fato da porosidade dos frits (discos que suportam e limitam o sorvente dentro do cartucho) utilizados em SPE serem normalmente de $20 \mu \mathrm{m}^{[19]}$. Os MIPs e NIP obtidos foram acondicionados em frascos plásticos fechados e mantidos à temperatura ambiente.

\subsection{Caracterização dos MIPs e NIP}

Os MIPs e NIP foram caracterizados por FTIR, MEV, DSC e TG.

Os espectros de absorção molecular na região do infravermelho, na faixa de 4000 a $650 \mathrm{~cm}^{-1}$, foram obtidos em espectrômetro FTIR modelo Nicolet 6700 da Thermo
Fisher SCIENTIFIC, usando acessório de reflexão total atenuada (ATR), com 64 varreduras e resolução de $4 \mathrm{~cm}^{-1}$ (cristal Ge), à temperatura ambiente $\left(\approx 20^{\circ} \mathrm{C}\right)$.

O equipamento de DSC utilizado, um Shimadzu modelo DSC-60, foi programado para aquecimento das amostras da temperatura ambiente $\left(\approx 20^{\circ} \mathrm{C}\right)$ a $300^{\circ} \mathrm{C}$, a uma razão de aquecimento de $10^{\circ} \mathrm{C} \cdot \mathrm{min}^{-1}$. O porta amostra utilizado foi de alumínio selado com furo e o gás de arraste, nitrogênio, com vazão de $50 \mathrm{~mL} \cdot \mathrm{min}^{-1}$. A massa das amostras analisadas variou entre 5,0 e 10,0mg.

A termogravimetria foi realizada com razão de aquecimento de $10^{\circ} \mathrm{C} \cdot \mathrm{min}^{-1}$, da temperatura ambiente $\left(\approx 20^{\circ} \mathrm{C}\right)$ até $600^{\circ} \mathrm{C}$, em porta amostra de platina e atmosfera de nitrogênio com vazão de $50 \mathrm{~mL} \cdot \mathrm{min}^{-1}$. O equipamento empregado foi um Shimadzu modelo TGA-50WS. A massa das amostras analisadas variou entre 5,0 e 10,0mg.

As microscopias dos MIPs e NIP foram realizadas em microscópio eletrônico de varredura (Marca: Hitachi, Modelo: TM3000) em 15,0kV. As imagens obtidas foram processadas utilizando o software TM3000. Todas as amostras foram analisadas à temperatura ambiente de $20^{\circ} \mathrm{C}$, aproximadamente. Esse microscópio opera sob baixo vácuo, portanto não necessita de metalização das amostras para obtenção das micrografias.

\subsection{Extração da fenilalanina dos MIPS}

Após a síntese dos MIPs, foi necessário proceder à remoção da molécula molde para que pudesse ocorrer a religação da mesma, quando da aplicação final do MIP. O método escolhido nesse trabalho, para a remoção da fenilalanina, foi extração por Soxhlet. Nesse método, sucessivas lavagens com uma mistura de metanol e ácido acético $(9: 1, \mathrm{v} / \mathrm{v})$ foram utilizadas até a extração completa da molécula molde, monitorada por meio de análise da solução eluente no espectrofotômetro UV-Vis (VARIAN, modelo Cary 50), sendo determinado, dessa forma, o tempo necessário para a extração. Pesaram-se 2,5g do polímero (MIP) resultante da síntese em papel de filtro Whatman, sendo ele fechado em forma de cartucho e transferido para o Soxhlet. Conectou-se ao Soxhlet, um balão tritubulado contendo inicialmente $300 \mathrm{~mL}$ de solução de metanol e ácido acético 9:1 (v/v). Utilizou-se uma das três vias para coleta do extrato e na outra foi colocado um termômetro para monitoramento da temperatura, programada para $65 \pm 2^{\circ} \mathrm{C}$ utilizando-se manta aquecedora (FANEM, modelo 178). Após 4 horas de extração, foi retirada uma alíquota de $10 \mathrm{~mL}$ do extrato e a mesma analisada em espectrofotômetro UVVis (VARIAN, modelo Cary 50), em comprimento de onda de 259nm para verificação da presença da fenilalanina. Confirmada a presença da molécula molde, todo o extrato era retirado do balão e substituído por uma nova solução de $300 \mathrm{~mL}$ de metanol e ácido acético 9:1 (v/v). Ao atingir uma

Tabela 1. Quantidades dos reagentes utilizadas na síntese dos MIPs com fenilalanina e do NIP.

\begin{tabular}{|c|c|c|c|c|c|c|}
\hline MIP / NIP & $\begin{array}{c}\text { Fenilalanina } \\
\text { (g) }\end{array}$ & $\begin{array}{c}\text { MAA } \\
(\mu \mathrm{L})\end{array}$ & $\begin{array}{c}\text { Razão "MM/MF" } \\
\text { (mg.mL-1) }\end{array}$ & $\begin{array}{c}\text { EGDMA } \\
(\mu \mathrm{L})\end{array}$ & $\begin{array}{c}\text { AIBN } \\
\text { (g) }\end{array}$ & $\begin{array}{c}\text { Clorofórmio } \\
(\mathrm{mL})\end{array}$ \\
\hline MIP-1 & 0,0172 & 682 & 25,2 & 4720 & 0,0200 & 5 \\
\hline MIP-2 & 0,0319 & 682 & 46,8 & 4720 & 0,0200 & 5 \\
\hline MIP-3 & 0,0863 & 3410 & 25,3 & 23600 & 0,1000 & 25 \\
\hline NIP-1 & 0 & 682 & 0 & 4720 & 0,0200 & 5 \\
\hline
\end{tabular}


concentração em torno de $200 \mu \mathrm{g} \cdot \mathrm{mL}^{-1}$, passou-se a utilizar um volume de $200 \mathrm{~mL}$ de solução para a extração com o objetivo de reduzir o consumo de solvente. Esse procedimento de extração foi repetido até o extrato não apresentar mais bandas de absorção em leitura no espectrofotômetro UV-Visível, indicando a ausência da fenilalanina, totalizando, dessa forma, um período de extração de 64 horas. Após a retirada da MM, o cartucho contendo MIP foi lavado com metanol ainda no Soxhlet, para a retirada do excesso de ácido, por um período de 4 horas, e então submetido ao vácuo em estufa à vácuo (Vacuoterm, modelo 6030A) à temperatura de $65 \pm 5^{\circ} \mathrm{C}$, para remoção do excesso de solvente e secagem.

\subsection{Ensaio de adsorção}

Para a realização deste ensaio, utilizaram-se todos os MIPs e o NIP sintetizados, bem como uma solução-controle, sem o polímero. Pesaram-se 25, 50 e $100 \mathrm{mg}$, em duplicata, de cada MIP e NIP em Erlenmeyers de 50mL. Na sequência, adicionaram-se, com o auxílio de micropipeta automática Eppendorf, $5 \mathrm{~mL}$ de solução aquosa de fenilalanina $\left(450 \mu \mathrm{g} . \mathrm{mL}^{-1}\right)$ em cada Erlenmeyer. Os Erlenmeyers foram colocados em banho térmico com agitador orbital (shaker) (NOVA ÉTICA, modelo 304D) com agitação por 72 horas a $25^{\circ} \mathrm{C}$. Posteriormente, as amostras contidas nos Erlenmeyers foram transferidas para tubos Falcon de $15 \mathrm{~mL}$ e centrifugadas em centrífuga (SPINLAB, modelo SL16 RAV) a 4000rpm por 30 minutos. O sobrenadante foi recolhido, filtrado e analisado em espectrofotômetro UV-Visível (VARIAN, modelo Cary 50) a 258nm. Para a realização dessa leitura, preparou-se uma curva analítica para a fenilalanina em solução aquosa, com concentração variando entre 20 e $450 \mu \mathrm{g} \cdot \mathrm{mL}^{-1}$. O mesmo procedimento para a solução-controle, sem polímero, foi realizado.

\section{Resultados e Discussão}

\subsection{Síntese dos MIPs e NIP}

Os MIPs e o NIP apresentaram aspecto cristalino, esbranquiçado e estrutura rígida. A formação do possível complexo "monômero funcional - molécula molde" ("MF-MM"), por meio de impressão não-covalente, é ilustrada na Figura 1. Não foi possível realizar a análise estrutural dos sítios de ligação dos MIPs devido à natureza amorfa do material e à distribuição heterogênea das estruturas dos sítios de ligações.

\subsection{Caracterização dos MIPs e NIP}

Os espectros FTIR referentes à fenilalanina e aos polímeros NIP-1 e MIP-1, MIP-2 e MIP-3, antes da extração da Phe, são apresentados na Figura 2. As principais bandas de absorção características dos grupos químicos presentes nos polímeros e na fenilalanina são apresentadas na Tabela 2 .

Nos espectros FTIR de todos os polímeros sintetizados e apresentados na Figura 2, foi possível notar as bandas características dos grupos químicos presentes nesses polímeros, com destaque para as bandas entre 2964 e $2957 \mathrm{~cm}^{-1}$, característica da deformação axial das ligações de $\mathrm{C}-\mathrm{H}$ de alifático, em $1722 \mathrm{~cm}^{-1}$, característica do estiramento da carbonila $(\mathrm{C}=\mathrm{O})$ de ácido carboxílico, e entre 1162 e $1153 \mathrm{~cm}^{-1}$, característica da deformação axial de C-O de ácido carboxílico.

Nos espectros FTIR para os MIPs e, diferentemente no espectro FTIR para o NIP, observam-se as bandas de absorção características de aminoácidos em 2414 e $2124 \mathrm{~cm}^{-1}$, deformação axial das ligações de C-H de anel aromático em $3067 \mathrm{~cm}^{-1}$ e a banda de absorção características da ligação $\mathrm{C}=\mathrm{O}$ de aminoácidos em $1563 \mathrm{~cm}^{-1}$. Também pode-se observar que essas bandas apresentaram-se mais intensas nos espectros FTIR para os MIPs 1 e 3, apresentando-se em menor intensidade para o MIP-2, o que permite inferir que a quantidade da Phe nesse MIP pode ser menor.

As micrografias obtidas para o NIP-1 e os MIP-1, MIP-2 e MIP-3, antes da extração da Phe, são apresentadas na Figura 3. Pode-se observar nessas micrografias que as polimerizações efetuadas levaram à produção de partículas irregulares. Tal morfologia é característica de MIPs e NIPs sintetizados pelo método de polimerização em massa. Aparentemente não se observou nenhuma diferença entre a micrografia para o NIP-1 e para os MIP-1, MIP-2 e MIP-3. A presença da Phe parece não ter afetado a morfologia superficial do polímero.

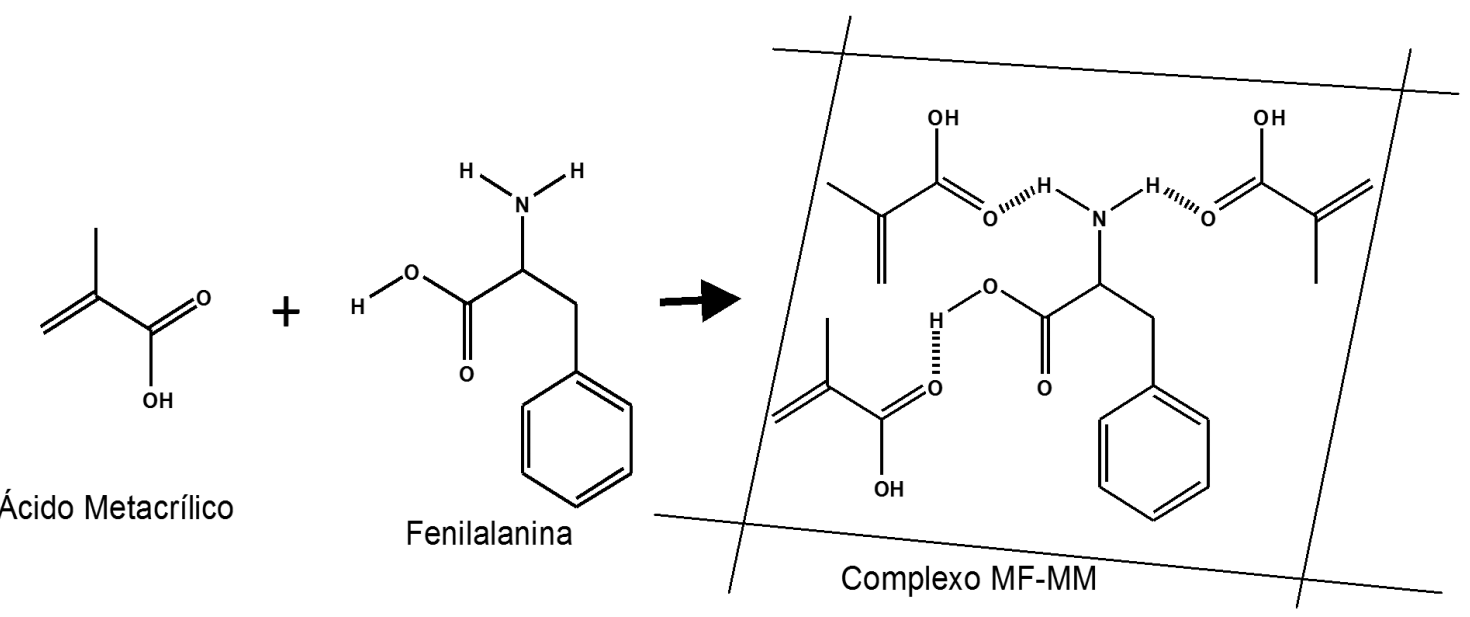

Figura 1. Representação da provável formação do complexo "MF-MM". 


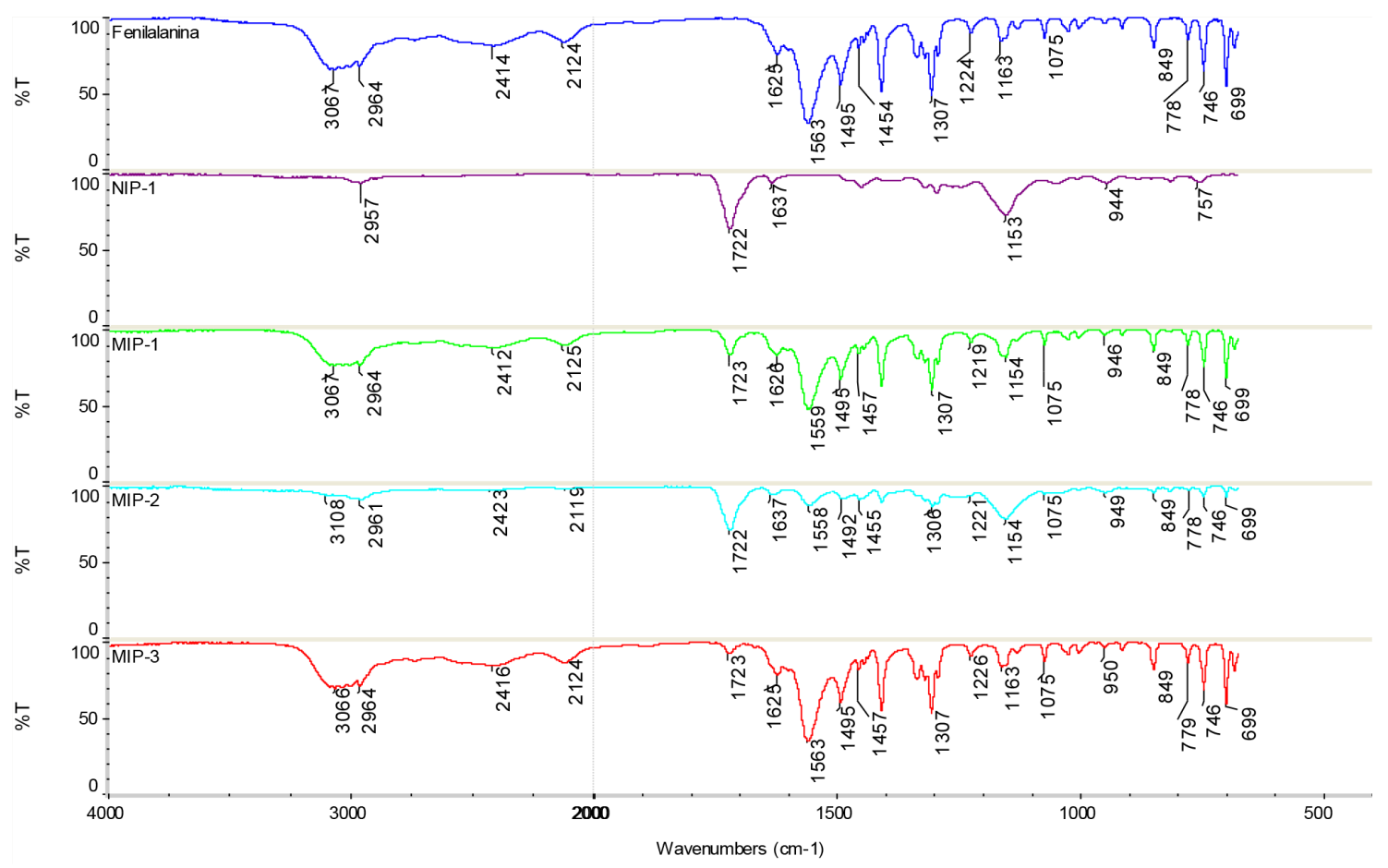

Figura 2. Espectros FTIR para a Phe, o NIP-1 e os MIP-1, MIP-2 e MIP-3 antes da extração da Phe.

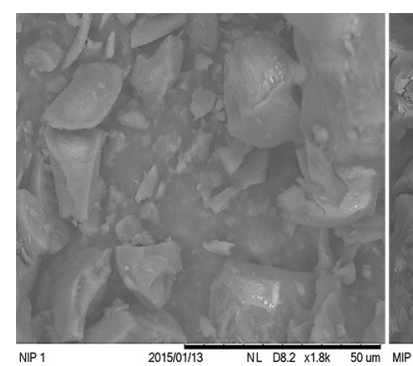

(a)

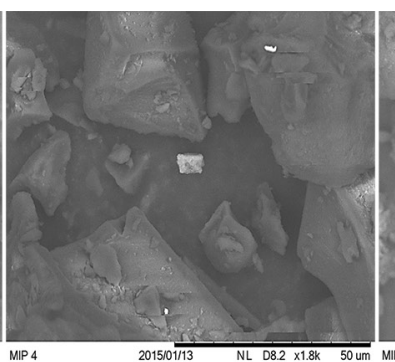

(b)

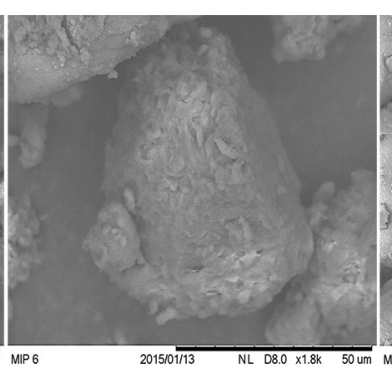

(c)

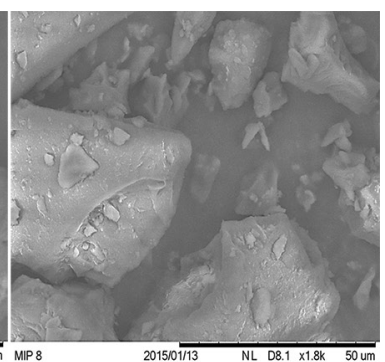

(d)

Figura 3. Micrografias do NIP-1 (a), MIP-1 (b), MIP-2 (c) e MIP-3 (d), antes da extração da Phe.

Tabela 2. Atribuições das principais bandas de absorção no espectro FTIR para os polímeros e a Phe.

\begin{tabular}{ccc}
\hline \multicolumn{2}{c}{ Número de onda observado $\left(\mathbf{c m}^{-1}\right)$} & Atribuição \\
\hline Phe & MIPs e NIP & deformação angular de C-H de anel aromático \\
\hline $849,778,746,699$ & - & proveniente da ligação C-Cl \\
- & 757 & deformação angular de O-H de ácido carboxílico \\
- & $950-944$ & estiramento de C-N de amina primária \\
1074 & - & deformação axial de C-O de éster \\
- & $1155-148$ & deformação axial de C-O de ácido carboxílico \\
1307,1163 & $1300-1250$ & deformação axial C-C de anel aromático \\
1453 & - & estiramento de C=O de aminoácidos \\
1563 & - & deformação axial de compostos aromáticos \\
1625,1500 & 1638 & estiramento dos grupos vinila C=C \\
- & 1720 & estiramento da carbonila (C=O) de ácido carboxílico \\
- & - & deformação axial de aminoácidos NH ${ }^{+}$ \\
2124 & 2900 & deformação axial de aminas com cargas positivas \\
2414 & $2960-2952$ & deformação axial de O-H de ácido carboxílico. \\
- & - & deformação axial das ligações de C-H de alifático \\
2964 & & deformação axial das ligações de C-H de anel aromático \\
3067 &
\end{tabular}


Observando as curvas TG para os MIPs (antes da extração) e o NIP-1 sintetizados (Figura 4), percebe-se que o perfil das curvas TG para todas essas amostras é bem semelhante, apresentando uma perda de massa entre a temperatura ambiente e $160^{\circ} \mathrm{C}$ e duas perdas de massa sequenciais entre 200 e $500^{\circ} \mathrm{C}$. A primeira perda de massa, em torno de $22 \pm 3,4 \%$ (exceto para o MIP-3), pode estar relacionada à presença de agente reticulante não reagido, visto que seu ponto de ebulição encontra-se entre 98 e $100^{\circ} \mathrm{C}$, e/ou algum solvente residual. Tal fato justifica uma maior perda, em torno de $40 \%$, para o MIP-3, que teve a quantidade de EGDMA aumentada em cinco vezes em relação aos outros MIPs e NIP. As outras duas perdas de massa, que totalizaram cerca de $75 \pm 2,4 \%$ e $60 \%$, aproximadamente, para o MIP-3, devem estar relacionadas à degradação das cadeias poliméricas dos MIPs e NIP e, também, da fenilalanina, no caso dos MIPs.

As curvas DSC para a Phe, o NIP-1 e os MIP-1, MIP-2 e MIP-3 antes da extração da Phe, são apresentadas na Figura 5.

Pode-se notar na curva DSC para a molécula molde (Phe), apresentada na Figura 5, existência de 3 eventos endotérmicos muito próximos entre 200 e $300^{\circ} \mathrm{C}$. Esses eventos podem estar relacionados à fusão da fenilalanina e de sua degradação, observada na curva TG por meio das duas perdas de massa

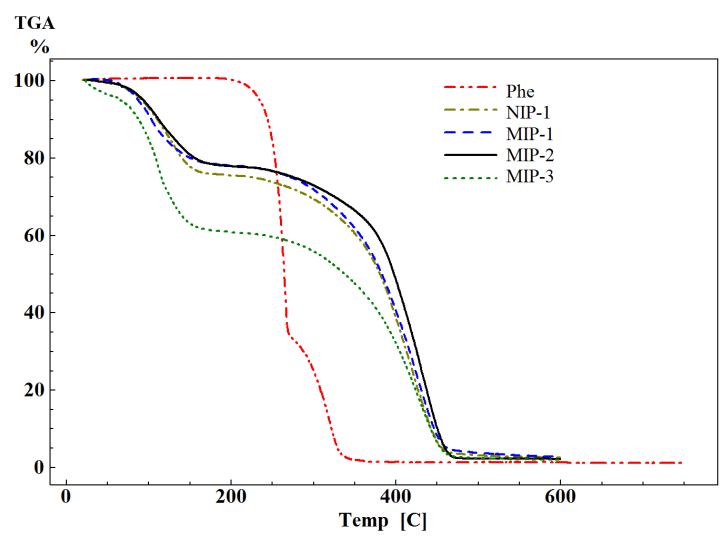

Figura 4. Curvas TG para a Phe, o NIP-1 e os MIP-1, MIP-2 e MIP-3 antes da extração da Phe.

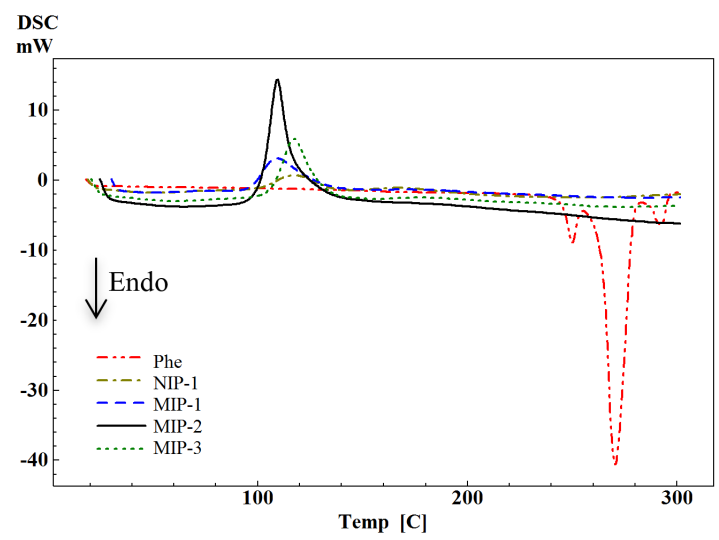

Figura 5. Curvas DSC para a Phe, o NIP-1 e os MIP-1, MIP-2 e MIP-3 antes da extração da Phe. consecutivas. Esses dois eventos térmicos para Phe, fusão e degradação, parece que ocorrem em temperaturas muito próximas.

As curvas DSC dos MIPs antes da extração da molécula molde e do NIP sintetizados, (Figura 5), apresentaram basicamente o mesmo perfil. Percebe-se claramente um evento exotérmico entre 80 e $160^{\circ} \mathrm{C}$. Acredita-se que esse evento possa estar relacionado ao fluxo líquido de calor devido à polimerização de moléculas de ácido metacrílico, ainda presentes na estrutura dos MIPs e NIP, e à vaporização do EGDMA e/ou algum solvente residual, ambos fenômenos ocorrendo com o aumento da temperatura e dentro do mesmo intervalo. A polimerização do MAA é extremamente exotérmica, prevalecendo sobre o evento endotérmico envolvendo a perda de massa, conforme foi observado nas curvas TG desses polímeros. As curvas DSC para os MIPs não apresentaram picos relacionados à fusão e degradação da Phe presente nesses polímeros. Talvez isso tenha ocorrido devido às interações dessa substância com as cadeias poliméricas dos MIPs, deixando de apresentar uma fusão cristalina e sua degradação ocorrendo em temperatura superiores, concomitante com as cadeias dos polímeros.

A partir das curvas DSC (Figura 5), não foi possível observar a temperatura de transição vítrea desses polímeros. Essa transição, caso exista, seria melhor visualizada em uma $2^{\mathrm{a}}$ corrida desses polímeros por DSC, análise que não foi executada nesse trabalho, pois isso apagaria a história térmica dos polímeros, dificultando o estudo da influência do processo de síntese realizado no comportamento deles.

\subsection{Extração da fenilalanina dos MIPs}

Os espectros FTIR referentes à fenilalanina e aos MIP-1, MIP-2 e MIP-3, após a extração da Phe, são apresentados na Figura 6.

As bandas características dos monômeros utilizados na síntese e que podem ser visualizadas nos espectros FTIR dos polímeros após a extração, apresentados na Figura 6, são as de EGDMA e MAA na região de $1700 \mathrm{~cm}^{-1}$, correspondentes ao estiramento de $\mathrm{C}=\mathrm{O}$ do grupo éster e carboxila do ácido, em $1150 \mathrm{~cm}^{-1}$, correspondente à deformação axial de C-O de éster e na região de 1300 a $1200 \mathrm{~cm}^{-1}$, característica de deformação axial de C-O de ácido carboxílico. Na região de $2900 \mathrm{~cm}^{-1}$ foram evidenciadas bandas de estiramento de $\mathrm{O}-\mathrm{H}$ de ácido carboxílico e C-H.

Além disso, foi possível observar nos espectros FTIR para os MIPs, após a extração (Figura 6), a ausência das bandas características da Phe como, por exemplo, em 2414 e $2124 \mathrm{~cm}^{-1}$, que são bandas características de aminoácidos, além da banda em $3067 \mathrm{~cm}^{-1}$, correspondente ao estiramento das ligações de C-H de anel aromático, o que é um forte indício da extração da fenilalanina.

As micrografias obtidas para o MIP-1, antes e após a extração da Phe, são apresentadas na Figura 7. Nota-se que o processo de extração de Phe afetou a morfologia do polímero, deixando-o com o aspecto mais poroso, após a extração.

As curvas TG para os MIPs 1, 2 e 3, após a extração, bem como para a fenilalanina, são apresentadas na Figura 8. Nota-se nas curvas TG para os MIPs o mesmo perfil de perda de massa, sendo possível observar três eventos de perda de 


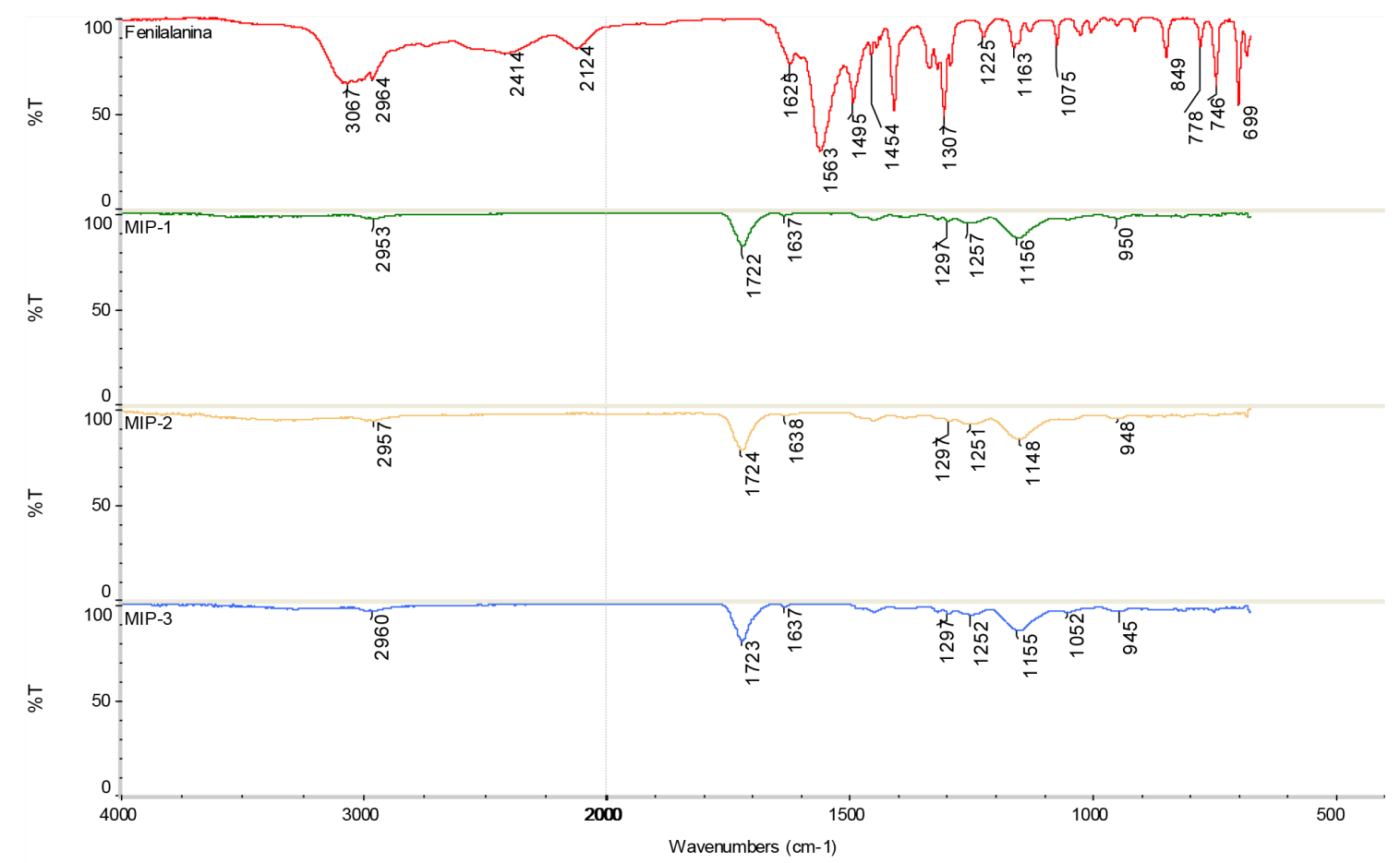

Figura 6. Espectros FTIR para a Phe e os MIP-1, MIP-2 e MIP-3 após extração da fenilalanina.

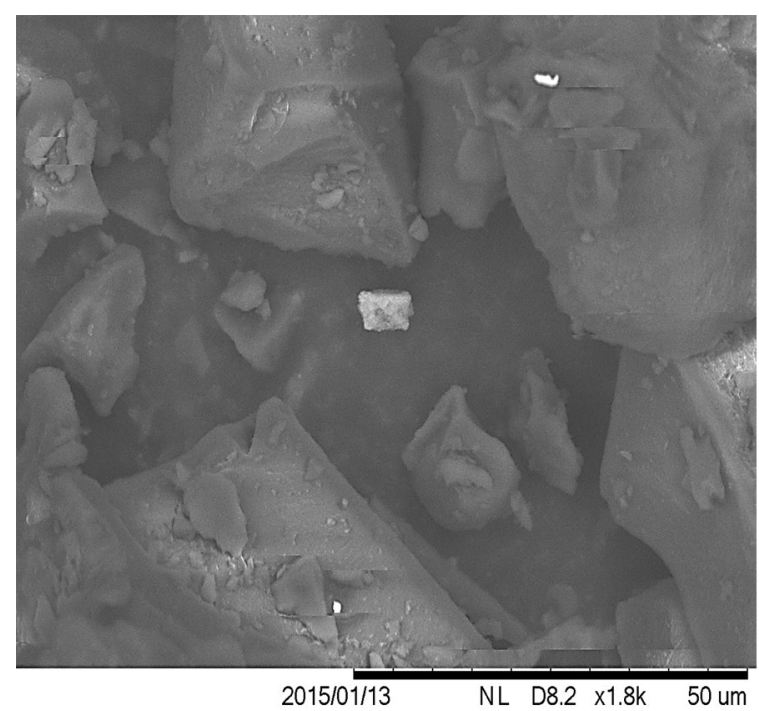

(a)

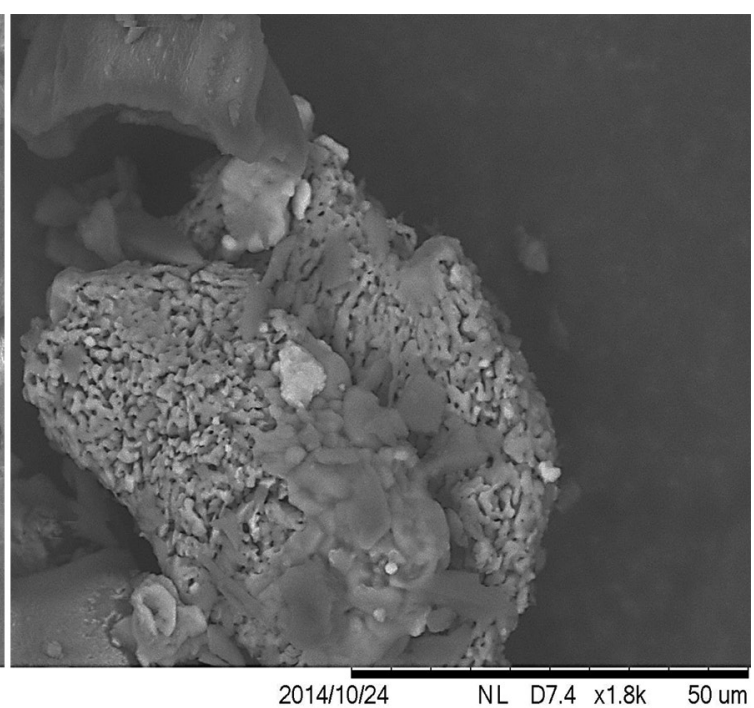

(b)

Figura 7. Micrografias do MIP-1 antes da extração da Phe (a) e após a extração (b).

massa. No primeiro evento, da temperatura ambiente até $200^{\circ} \mathrm{C}$, ocorre uma perda de massa entre 1 e $3 \%$ da quantidade inicial de massa analisada, que pode estar relacionada com a presença de solvente residual. Entre 200 e $500^{\circ} \mathrm{C}$ observam-se duas perdas de massa consecutivas em torno de $95 \%$, possivelmente proveniente da decomposição de metacrilatos (degradação das cadeias poliméricas dos MIPs). Comparando as curvas TG dos MIPs, após extração da Phe, com a curva TG da Phe, percebe-se que esses polímeros não contêm essa substância, indicando que o processo de extração dela foi eficiente.
As curvas DSC para a Phe e os MIP-1, MIP-2 e MIP-3 após a extração da Phe, são apresentadas na Figura 9.

Percebe-se um evento endotérmico entre a temperatura ambiente e $120^{\circ} \mathrm{C}$ nas curvas DSC para os MIPs, possivelmente devido à presença de solvente residual proveniente do processo de extração da fenilalanina. A partir de $180^{\circ} \mathrm{C}$ nota-se o início de outro evento endotérmico, pouco intenso e largo, talvez relacionado ao início da fusão e degradação dos polímeros. Comparando a curva DSC para a Phe com as curvas DSC para os MIPs, poderia utilizar-se da suposição 
feita anteriormente, para a situação dos MIPs antes da extração da Phe. No entanto, em função dos resultados apresentados por FTIR e TG, acredita-se que ela não esteja presente nesses polímeros.

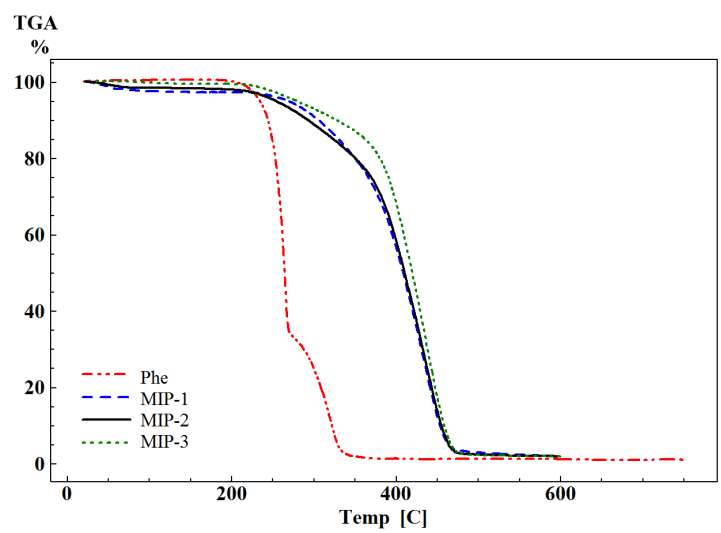

Figura 8. Curvas TG para a Phe e os MIP-1, MIP-2 e MIP-3 após a extração da Phe.

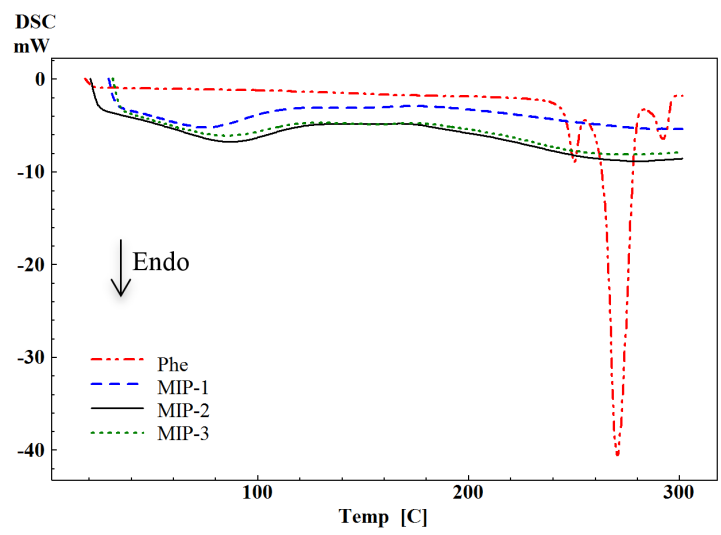

Figura 9. Curvas DSC para a Phe e os MIP-1, MIP-2 e MIP-3 após a extração da Phe.

\subsection{Ensaio de adsorção}

$\mathrm{O}$ ensaio de adsorção foi realizado de forma a avaliar a capacidade de reconhecimento molecular dos polímeros sintetizados. Assim, a adsorção da fenilalanina nos MIPs (após a extração de Phe) e NIP foi verificada variando a quantidade de polímero e mantendo a concentração inicial da solução entre 448,9 e $449,8 \mu \mathrm{g} \cdot \mathrm{mL}^{-1}$. Os cálculos para o ensaio de adsorção foram feitos determinando a concentração livre de Phe no sobrenadante, de acordo com a curva analítica de Phe em água construída antes do ensaio. A concentração de Phe adsorvida (C, em $\mu \mathrm{g} \cdot \mathrm{mL}^{-1}$ ) pelos MIPs e NIP foi determinada pela diferença entre a concentração inicial da solução (I, em $\mu \mathrm{g} \cdot \mathrm{mL}^{-1}$ ) e a concentração de analito livre $\left(\mathrm{F}, \mathrm{em} \mu \mathrm{g} \cdot \mathrm{mL}^{-1}\right)$. A taxa de adsorção da Phe $\left(\mathrm{T}_{\mathrm{ad}}\right.$, em \%) foi calculada pela relação: $T_{a d}=(C / I) \times 100$.

Os resultados do estudo de adsorção contendo a taxa de adsorção da fenilalanina nos polímeros MIPs e NIP são apresentados nas Tabelas de 3 a 6 .

As taxas de adsorção da fenilalanina em função das massas dos polímeros MIP-1, MIP-2, MIP-3 e NIP-1 utilizadas durante o ensaio, são apresentadas na Figura 10.

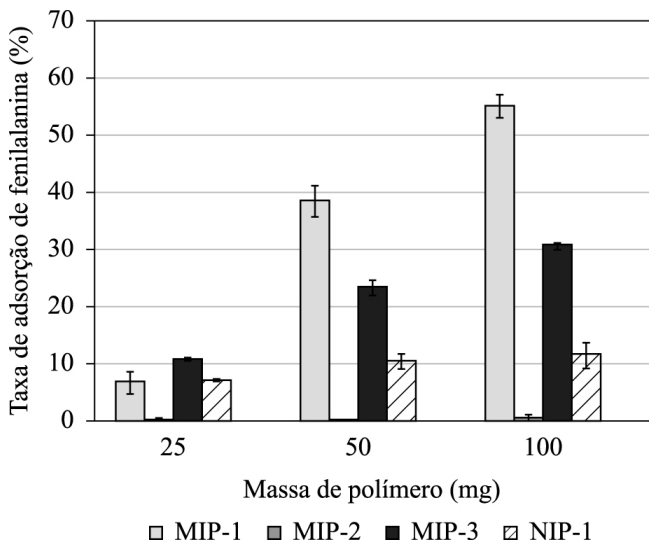

Figura 10. Taxas de adsorção da fenilalanina em função das massas dos MIP-1, MIP-2, MIP-3 e NIP-1.

Tabela 3. Ensaio de adsorção variando a quantidade (massa) do polímero MIP-1.

\begin{tabular}{cccccc}
\hline $\begin{array}{c}\text { Massa } \\
(\mathbf{m g})\end{array}$ & $\begin{array}{c}(\mathbf{I}) \\
\left(\boldsymbol{\mu g} \cdot \mathbf{m L}^{-\mathbf{1}}\right)\end{array}$ & $\begin{array}{c}\mathbf{( F )} \\
\left(\boldsymbol{\mu g} \cdot \mathbf{m L}^{-1}\right)\end{array}$ & $\begin{array}{c}(\mathbf{C}) \\
\left(\boldsymbol{\mu g} \cdot \mathbf{m L}^{-1}\right)\end{array}$ & $\begin{array}{c}\mathbf{T}_{\text {ad }} \\
(\mathbf{\%})\end{array}$ & $\begin{array}{c}\text { Média e desvio } \\
\mathbf{p a d r a ̃ o ~ d a ~} \mathbf{T}_{\text {ad }}(\mathbf{\%})\end{array}$ \\
\hline 25 & 448,9 & 411,4 & 37,5 & 8,35 & \\
25 & 448,9 & 423,3 & 25,6 & 5,70 & $7,03 \pm 1,9$ \\
50 & 448,9 & 267,2 & 181,7 & 40,48 & $38,58 \pm 2,7$ \\
50 & 448,9 & 284,3 & 164,6 & 36,67 & $55,18 \pm 2,0$ \\
100 & 448,9 & 207,5 & 241,4 & 53,78 & 56,58 \\
100 & 448,9 & 194,9 & 254 & & \\
\hline
\end{tabular}

Tabela 4. Ensaio de adsorção variando a quantidade (massa) do polímero MIP-2.

\begin{tabular}{cccccc}
\hline $\begin{array}{c}\text { Massa } \\
(\mathbf{m g})\end{array}$ & $\begin{array}{c}(\mathbf{I}) \\
\left(\boldsymbol{\mu g} \cdot \mathbf{m L}^{-1}\right)\end{array}$ & $\begin{array}{c}\mathbf{F}) \\
\left(\boldsymbol{\mu g} \cdot \mathbf{m L}^{-1}\right)\end{array}$ & $\begin{array}{c}(\mathbf{C}) \\
\left(\boldsymbol{\mu g} \cdot \mathbf{m L}^{-1}\right)\end{array}$ & $\begin{array}{c}\mathbf{T}_{\text {ad }} \\
(\mathbf{\%})\end{array}$ & $\begin{array}{c}\text { Média e desvio } \\
\mathbf{p a d r a ̃ o ~ d a ~} \mathbf{T}_{\text {ad }}(\mathbf{\%})\end{array}$ \\
\hline 25 & 449,8 & 446,9 & 2,9 & 0,64 & \\
25 & 449,8 & 448,9 & 0,9 & 0,20 & $0,42 \pm 0,3$ \\
50 & 449,8 & 446,8 & 3 & 0,67 & $0,60 \pm 0,1$ \\
50 & 449,8 & 447,4 & 2,4 & 0,53 & $0,79 \pm 0,7$ \\
100 & 449,8 & 444,1 & 5,7 & 1,27 & 0,31 \\
100 & 449,8 & 448,4 & 1,4 & & \\
\hline
\end{tabular}


Tabela 5. Ensaio de adsorção variando a quantidade (massa) do polímero MIP-3.

\begin{tabular}{|c|c|c|c|c|c|}
\hline $\begin{array}{c}\text { Massa } \\
(\mathrm{mg})\end{array}$ & $\begin{array}{c}\text { (I) } \\
\left(\mu \mathrm{g} \cdot \mathrm{mL}^{-1}\right)\end{array}$ & $\begin{array}{c}(\mathbf{F}) \\
\left(\mu \mathrm{g} \cdot \mathrm{mL}^{-1}\right)\end{array}$ & $\begin{array}{c}(\mathrm{C}) \\
\left(\mu \mathrm{g} \cdot \mathrm{mL}^{-1}\right)\end{array}$ & $\begin{array}{c}T_{\text {ad }} \\
(\%)\end{array}$ & $\begin{array}{c}\text { Média e desvio } \\
\text { padrão da } T_{a d}(\%)\end{array}$ \\
\hline 25 & 449,8 & 401,3 & 48,5 & 10,78 & \\
\hline 25 & 449,8 & 399,1 & 50,7 & 11,27 & $11,03 \pm 0,3$ \\
\hline 50 & 449,8 & 348,1 & 101,7 & 22,61 & \\
\hline 50 & 449,8 & 339,8 & 110 & 24,46 & $23,54 \pm 1,3$ \\
\hline 100 & 449,8 & 309,6 & 140,2 & 31,17 & \\
\hline 100 & 449,8 & 312,9 & 136,9 & 30,4 & $30,81 \pm 0,5$ \\
\hline
\end{tabular}

Tabela 6. Ensaio de adsorção variando a quantidade (massa) do polímero NIP-1.

\begin{tabular}{|c|c|c|c|c|c|}
\hline $\begin{array}{c}\text { Massa } \\
(\mathrm{mg})\end{array}$ & $\begin{array}{c}(\mathrm{I}) \\
\left(\mu \mathrm{g} \cdot \mathrm{mL}^{-1}\right)\end{array}$ & $\begin{array}{c}(\mathrm{F}) \\
\left(\mu \mathrm{g} . \mathrm{mL}^{-1}\right)\end{array}$ & $\begin{array}{c}(\mathrm{C}) \\
\left(\mu \mathrm{g} \cdot \mathrm{mL}^{-1}\right)\end{array}$ & $\begin{array}{c}T_{\text {ad }} \\
(\%)\end{array}$ & $\begin{array}{c}\text { Média e desvio } \\
\text { padrão da } T_{a d}(\%)\end{array}$ \\
\hline 25 & 449,8 & 416,3 & 33,5 & 7,45 & \\
\hline 25 & 449,8 & 419,5 & 30,3 & 6,74 & $7,1 \pm 0,5$ \\
\hline 50 & 449,8 & 403,6 & 46,2 & 10,27 & \\
\hline 50 & 449,8 & 401,3 & 48,5 & 10,78 & $10,53 \pm 0,4$ \\
\hline 100 & 449,8 & 401,8 & 48,0 & 10,67 & \\
\hline 100 & 449,8 & 400,4 & 49,4 & 10,98 & $10,83 \pm 0,2$ \\
\hline
\end{tabular}

A partir das Tabelas 3 a 6 ou da Figura 10, percebe-se que, para os MIPs 1 e 3, com o aumento da massa de polímero de 25 para $100 \mathrm{mg}$, a quantidade de fenilalanina adsorvida também aumenta, passando de 7,0 $\pm 1,9$ para $55,2 \pm 2,0$ e de $11,0 \pm 0,3$ para $30,8 \pm 0,5$, respectivamente. Esses resultados indicam que, mantendo-se fixa a relação entre a quantidade de MM e MF, o aumento de massa de polímero nesses MIPs tende a aumentar a quantidade de Phe adsorvida de forma bem significativa, dentro da variação de massa estudada.

Comparando-se os MIPs 1 e 3, nota-se que as quantidades de MM, MF, AR, IR e solvente (Tabela 1) foram aumentadas em 5 vezes do MIP-1 para o MIP-3, sendo mantido constante o tempo de reação em 6 horas. Ambos apresentaram a mesma tendência quanto à adsorção de fenilalanina, porém o MIP-1 adsorveu uma quantidade maior de Phe com o aumento de massa do polímero, exceto para $25 \mathrm{mg}(7,0 \pm 1,9$ para o MIP-1 e $11,0 \pm 0,3$ para o MIP-3). Apesar da relação estequiométrica ter sido mantida constante para todas essas variáveis de síntese, em termos de estrutura obtida durante a polimerização, parece que foram obtidos mais sítios específicos no MIP-1, para permitir a interação com a Phe. Esse maior número de sítios pode ser devido à reação de formação desses polímeros ser um processo aleatório, permitindo essa diferença. Ou então, pode ser que o tempo de reação para o MIP-3 tenha sido menor do que o necessário para a formação de número de sítios similar ou próximo dos obtidos para o MIP-1. Para melhor entendimento dessa questão é necessária a obtenção de outros MIPs variando-se as condições de síntese, bem como outros ensaios de adsorção de Phe.

Ao comparar os resultados de taxa de adsorção de Phe obtidos com os MIPs 1 e 3 com o NIP 1 (apresentados nas Tabelas 3, 5, e 6 e na Figura 10), percebe-se claramente a influência da fenilalanina na formação de sítios específicos e sua interação com o MF durante o processo de polimerização dos MIPs. Aúnica diferença entre os MIPs 1 e 3 com o NIP 1 é que esse último foi sintetizado sem a Phe. As quantidades usadas nas variáveis de síntese (Tabela 1) foram as mesmas, exceto para o MIP-2 que teve um aumento na massa de Phe de 1,85 vezes em relação ao MIP-1 e para o MIP-3, que teve todos os valores dessas variáveis multiplicados por 5 .
Os MIPs, após extração da Phe, apresentaram a mesma taxa de adsorção, aproximadamente, com $25 \mathrm{mg}$ de massa de polímero. Porém, com o aumento dessa massa para 50 e 100mg a taxa de adsorção de Phe aumentou significativamente. Para o MIP-1, comparado ao seu polímero controle, NIP-1, o aumento foi de $28 \%$ e $44 \%$, respectivamente. Já o MIP-3 apresentou um acréscimo de $13 \%$ e $20 \%$, respectivamente, em relação ao seu NIP controle, NIP-1. Portanto, há evidências de que o MF (ácido metacrílico) sintetizado com a MM (fenilalanina) permite um maior número de interações específicas MF-MM no polímero sintetizado com a MM e após extração da mesma desse polímero do que o polímero sintetizado sem a MM.

Dentre os MIPs sintetizados, o MIP-2 foi o polímero impresso que menos adsorveu a MM, observando-se taxas de adsorção abaixo de 2\%. Quando comparado com a taxa de adsorção observada para o NIP-1, percebe-se que o MIP-2 não foi seletivo para fenilalanina, visto que a taxa mínima de adsorção do NIP foi de $7,1 \pm 0,5 \%$. Tal fato pode ser explicado em virtude da variável molécula molde, no MIP-2, ter sido aumentada quase o dobro $(1,85)$ em relação ao MIP-1, enquanto que a quantidade de monômero funcional não foi alterada. Para que se obtenha MIPs com sítios mais específicos, é necessário que se tenha uma quantidade suficiente de MF para complexar com todos os possíveis sítios ativos da MM e, assim, obter sítios específicos. A interação analito-monômero é governada por um processo em equilíbrio, quantidades superiores do monômero em relação ao analito devem ser empregadas com intuito de deslocar o equilíbrio, formando assim maior quantidade de complexos "analito-monômero". Nesse caso, o aumento da MM pode ter desfavorecido a formação desse complexo, impedindo ou diminuindo drasticamente a criação dos sítios específicos para essa interação.

A partir desses resultados, pode-se inferir que uma maior massa de polímero proporciona maior área de contato, e, portanto, maior adsorção da molécula durante um mesmo intervalo de tempo. 


\section{Conclusão}

Os MIPs e NIP foram sintetizados e caracterizados por FTIR, MEV, TG e DSC. Antes da extração da Phe foi possível observar, por FTIR, as bandas características de seus grupos químicos nos MIPs, com destaque para as bandas de aminoácidos. O processo de extração da Phe dos MIPs foi eficiente, uma vez que os espectros FTIR e as curvas TG, obtidos para os MIPs após a extração, não indicaram a presença da Phe. Conforme observado por MEV, um dos MIPs sintetizado teve sua morfologia superficial afetada pelo processo de extração da Phe, deixando-o com $\mathrm{o}$ aspecto mais poroso.

Quanto ao estudo de adsorção, os MIPs apresentaram maior capacidade adsortiva pela Phe, obtendo-se taxa média de adsorção de até $56 \%$. Comparando-os ao NIP, para o qual foi obtida taxa de adsorção próxima de $11 \%$, foi possível concluir que esse MIP apresentou-se específico para a determinação da MM Phe, com grande potencial para aplicação como adsorvente em SPE.

\section{Agradecimentos}

Os autores agradecem à FAPEMIG, CAPES, CNPq, CEMIG e PETROBRAS pelo suporte financeiro.

\section{Referências}

1. Pauling, L. J. A. (1940). Theory of the structure and process of formation of antibodies. Journal of the American Chemical Society, 62(10), 2643-2657. http://dx.doi.org/10.1021/ ja01867a018.

2. Dickey, F. H. (1949). The preparation of specific adsorbents. Proceedings of the National Academy of Sciences of the United States of America, 35(5), 227-229. http://dx.doi.org/10.1073/ pnas.35.5.227. PMid:16578311.

3. Fernandes, R. M. T. (2012). Polímeros de impressão molecular para extração seletiva de fármacos em matrizes biológicas e determinação por LC-MS/MS e MS/MS (Tese de doutorado). Universidade Estadual de Campinas, Campinas.

4. Tarley, C. R. T., Sotomayor, M. D. P. T., \& Kubota, L. T. (2005). Polímeros biomiméticos em química analítica. Parte 1: Preparo e aplicações de MIP ("Molecularly Imprinted Polymers") em técnicas de extração e separação. Quimica Nova, 28(6), 10761086. http://dx.doi.org/10.1590/S0100-40422005000600024.

5. Hung, C., Huang, H., \& Hwang, C. (2005). Chiral separations of mandelic acid by HPLC using molecularly imprinted polymers. Eclética Química, 30, 67-73. http://dx.doi.org/10.1590/S010046702005000400009.

6. Suedee, R., Seechamnanturakit, V., Canyuk, B., Ovatlarnporn, C., $\&$ Martin, G. P. (2006). Temperature sensitive dopamine-imprinted (N,N-methylene-bis-acrylamide cross-linked) polymer and its potential application to the selective extraction of adrenergic drugs from urine. Journal of Chromatography. A, 1114(2), 239-249. http://dx.doi.org/10.1016/j.chroma.2006.02.033. PMid:16530207.
7. Mosbach, K. (1994). Molecular imprinting. Trends in Biochemical Sciences, 19(1), 9-14. http://dx.doi.org/10.1016/09680004(94)90166-X. PMid:8140624.

8. Andersson, L., Paprica, A., \& Arvidsson, T. (1997). A highly selective solid phase extraction sorbent for pre-concentration of sameridine made by molecular imprinting. Chromatographia, 46(1), 57-62. http://dx.doi.org/10.1007\%2FBF02490930.

9. Koster, E. H. M., Crescenzi, C., den Hoedt, W., Ensing, K., \& de Jong, G. J. (2001). Fibers coated with molecularly imprinted polymers for solid-phase microextraction. Analytical Chemistry, 73(13), 3140-3145. http://dx.doi.org/10.1021/ac001331x. PMid:11467565.

10. Martín-Esteban, A. (2001). Molecularly imprinted polymers: new molecular recognition materials for selective solid-phase extraction of organic compounds. Fresenius' Journal of Analytical Chemistry, 370(7), 795-802. http://dx.doi.org/10.1007/ s002160100854. PMid:11569855.

11. Caro, E., Marce, R. M., Borrull, F., Cormack, P., \& Sherrington, D. (2006). Application of molecurlay imprinted polymers to solid phase extraction of compounds from environmental and biological samples. Trends in Analytical Chemistry, 25(2), 143-153. http://dx.doi.org/10.1016/j.trac.2005.05.008.

12. Tamayo, F. G., Turiel, E., \& Martín-Esteban, A. (2007). Molecularly imprinted polymers for solid-phase extraction and solid-phase microextraction: Recent developments and future trends. Journal of Chromatography. A, 1152(1-2), 32-40. http:// dx.doi.org/10.1016/j.chroma.2006.08.095. PMid:17010356.

13. Yang, J., Hu, Y., Cai, J. B., Zhu, X. L., Su, Q. D. (2006). A new molecularly imprinted polymer for selective extraction of cotinine from urine by solid-phase extraction. Analytical and Bioanalytical Chemistry, 384(3), 761-768. http://dx.doi. org/10.1007\%2Fs00216-005-0221-4.

14. Pérez-Moral, N., \& Mayes, A. G. (2004). Comparative study of imprinted polymer particles prepared by different polymerisation methods. Analytica Chimica Acta, 504(1), 15-21. http://dx.doi. org/10.1016/S0003-2670(03)00533-6.

15. Clark, H. L. M. (2010). Remoção de fenilalanina por adsorvente produzido a partir da torta prensada de grãos defeituosos de café (Dissertação de mestrado). Universidade Federal de Minas Gerais, Belo Horizonte.

16. Nelson, D. L., \& Cox, M. M. (2011). Princípios de bioquímica de Lehninger (5. ed.). Porto Alegre: Artmed.

17. Spivak, D. A. (2005). Optimization, evaluation, and characterization of molecularly imprinted polymers. Advanced Drug Delivery Reviews, 57(12), 1779-1794. http://dx.doi.org/10.1016/j. addr.2005.07.012. PMid:16260064.

18. Al-Kindy, S., Badía, R., Suárez-Rodríguez, J. L., \& Díaz-García, M. E. (2000). Molecularly imprinted polymers and optical sensing applications. Critical Reviews in Analytical Chemistry, 30(4), 291-309. http://dx.doi.org/10.1080/10408340008984162.

19. Peçanha, B. R. B., Dias, L. R. S., Spinelli, E., \& Muri, E. M. F. (2013). Polímeros de impressão molecular obtidos através de polimerização por precipitação e sua aplicação na técnica de extração em fase sólida. Polímeros: Ciência e Tecnologia, 23(4), 509-513. http://dx.doi.org/10.4322/polimeros.2013.055.

Enviado: Fev. 17, 2015 Revisado: Maio 15, 2015 Aceito: Jun. 01, 2015 